\title{
Measuring the implementation of injury prevention programs in state health agencies
}

\author{
Charlyn E Cassady, Deborah A Orth, Bernard Guyer, Malcolm L Goggin
}

\begin{abstract}
Objective-Injury prevention programs have been implemented with varying degrees of success in the United States. The objective of this study was to identify the variables that influence the successful implementation of injury prevention programs.

Methods-The key indicators of implementation success and its correlates were identified through consultation with a panel of experts. This consultation informed the content of a mail questionnaire sent to all United States state health departments, followed by telephone interviews. Data were analyzed using factor analysis and regression to identify significant relationships between variables.
\end{abstract}

Results-Data were obtained from 64 programs, representing 44 states; these included 24 programs in injury control units, 12 in maternal and child health units, 10 in health promotion/education units; and eight in emergency medical services units. Analysis identified four factors that are associated with an index of successful injury prevention program implementation; (1) participation and advocacy by constituent groups; (2) organizational capacity; (3) administrative control; and (4) attributes of relevant policies.

Conclusions-Findings indicated that constituent participation (the extent and efficacy of constituency support and advocacy) and organizational capacity (a function of program staff and their skill levels) had the greatest influence on successful program implementation. Support from advocacy groups and knowledgeable staff members, whose time is dedicated to the program, are critical for conducting the activities necessary for successful implementation of these programs.

(Injury Prevention 1997; 3: 94-99)

Keywords: implementation; advocacy; organizational capacity.

Whether measured by mortality, morbidity, disability, years of productive life lost, or economic cost to society, injury is a major public health problem that, during the $1980 \mathrm{~s}$, received unprecedented attention. As the fourth leading cause of death among all age groups in the United States, injuries kill more than 142000 Americans each year and cause more than 62 million persons to require medical attention, costing the nation approxio mately $\$ 133.2$ billion annually. ${ }^{1}$

The federal government has given increasing attention to the problem of injury and violencey The Healthy People 2000-National Health. Promotion and Disease Prevention Objectives. document details 22 objectives that addresड unintentional injuries, suicide, and violences identifies special population target groups, an recommends legislative revisions and environio mental modifications. ${ }^{2}$ The Center for Injuris Prevention and Control was created at the Centers for Disease Control and Prevention to. address the problem. ${ }^{3}$ Numerous agencies and foundations have funded workshops, as well a⿸户㔾 regional, state, and community level injury prevention projects. In addition, several majogo publications, including Injury in America: $A$ Continuing Health Problem, and Cost of Injury io the United States: A Report to Congress have appeared. ${ }^{45}$ In particular, Injury Prevention Meeting the Challenge was designed to help state and local health departments develop injury prevention activities. ${ }^{6}$

Increased visibility and funding, however, $\mathrm{d} \mathrm{z}^{\mathrm{z}}$ not guarantee the uniform implementation of effective injury prevention programs at the state or local level. To implement a policy of mandate is to put that policy into effece through interpretation and operationalizatio of original legislative, or executive, intents marshalling and allocating resources, coordi nating activities, building an effective systen for delivering services, and monitoring and evaluating program operations. Many of those who study implementation equate success with compliance; that is, putting policies into place quickly and with few modifications. In this paper, we treat implementation 'success' as the incorporation of certain critical programmatie activities; for example, community involve ment or the use of program evaluation technir ques to assess program outcomes Implementation research is problem solving focusing on the process of putting a plan into action by identifying the factors that lead to successful policy implementation, or by pin pointing impediments to successful implement tation. Several studies have explaine $\vec{\phi}$ variations in implementation across programs time, or units of government in terms of attributes of the policy, the implementors? their organizations, or the environment in which decisions and actions take place. ${ }^{7}$

Results of such studies also provide insight into the reasons for failure. Mazmanian and Sabatier linked minimal success in policy implementation with ambiguous policy directives; lack of supportive agencies and constituency; an unconvincing program rationale; and inadequate monitoring or oversight practices. ${ }^{8}$ 
While some of these obstacles-for example, a state's ailing economy-cannot be easily changed, other factors are capable of manipulation. The principal purposes of this paper are to shed light on the part that certain critical factors play in increasing the likelihood that injury prevention programs will be implemented successfully. To these ends, this paper reports results of a two year study of the implementation of 64 injury prevention programs in 44 states. After describing the characteristics of injury prevention programs included in the sample and outlining our approach, we identify those factors that seem to facilitate or inhibit implementation.

\section{Methods}

MEASURES

An advisory group for this project was organized of experts in the injury prevention/ control field; they represented a wide range of professionals: researchers, program administrators, policy specialists, and educators. The group participated in the development of the conceptual framework that would guide survey development and analysis; recommended content and wording of survey questions; and reviewed draft survey instruments. It undertook the challenge of identifying the characteristics of a 'successfully implemented' injury prevention/control program. The group reached consensus on five activities that were felt to be critical indicators of successful implementation: legislative activities, surveillance, monitoring and evaluation, community involvement with the injury program, and the ability to create a permanent place for the program within the state agency (institutionalization). The extent to which each of these activities is present indicates whether the program has been effectively implemented.

It should be understood that in this study we are not evaluating injury prevention/control programs on the basis of performance outcomes, for example, number of head or spinal cord injuries prevented. An assessment of implementation success differs from an evaluation of program success. Ideally, programs that are successfully implemented will have an impact on the incidence of injuries. This may not always be the case, however, because the intervention components of the program may not cover the full breadth of injury hazards or be powerful enough to overcome all of the societal or environmental factors that predispose to injury occurrences. Therefore, assessment of program implementation provides a complement to the evaluation of program effectiveness.

The appendix shows the five indicators that are combined to form the index of successful implementation of injury prevention programs-the dependent variable in the study. In addition, this research seeks to identify the correlates of success, that is, the factors that contribute to, or hinder, effective implementation (ML Goggin, S Laubacher, unpublished paper). ${ }^{7-9}$ We examined four 'critical' variables that theoretically ought to affect implementa- tion outcomes: attributes of policy directives, degree of administrative control, organizational capacity, and ecological capacity.

The attributes of policy directives that affect the choices and behavior of the program implementors are operationalized as the pertinence of state policy directives, the credibility of policies as a realistic solution, and the clarity and consistency of the policies. Administrative control is the degree of discretion that program officials have over critical administrative decisions, staff assignments, budgeting, contacts with other state and local officials, and program priorities. Organizational capacity is operationalized as the number of personnel assigned to the injury prevention program and their level of training and experience in the field.

Ecological capacity is a multidimensional concept that captures attributes of the environment which structure public health programs. Factor analysis indicates that the various aspects of ecological capacity measured by this study form five discrete dimensions, each of which are included as separate variables in this analysis. The five variables include several indicators. They are: problem salience (the attention to the problem of injury and to injury prevention by elected officials and agency heads); constituent participation (the extent and efficacy of constituency support and advocacy); support by elected officials; media attention; and the economy (economic and budgetary conditions, as perceived by the program personnel participating in this study).

\section{DATA COLLECTION}

The study participants were public officials in state level health agencies. Within these agencies, several units may engage in injury control activities, including free standing injury pervention programs, maternal and child health units, epidemiology units, emergency health services, or health promotion units. Directors of these five types of administrative units in every state were mailed survey packets and invited to participate if their program was involved in any level of injury prevention or control activities. The unit of analysis for the project is the individual injury prevention program, not individual states.

Self administered, written questionnaires containing 70 items in multiple choice and fill-in table format were designed to gather both objective and subjective data. They included the department/program's injury prevention activities, funding sources, program organization and structure, characteristics of personnel, available resources, significant barriers encountered, and staff development needs. Follow up telephone interviews were conducted after the completed questionnaires had been received. This interview used 11 open ended questions that addressed the origins of the program; reasons for delays in the implementation process; specific barriers encountered in the implementation process; strategies used to overcome those barriers; and efforts to institutionalize injury prevention activities or programs in the state health 
department. Responses to all items were scored using a Likert scale of criteria developed by the researchers in collaboration with the advisory group. Both instruments were pretested with three injury prevention or control programs who reviewed and commented on content and design before printing the final versions. The instruments and details of variable construction are available upon request.

\section{ANALYSIS}

The data collected by the mail questionnaire and the telephone interviews are combined to create the variables for analysis. Each variable is an index combining several measures of a concept or attribute. These combinations are factor analyzed (using STATA's iterated principal factors routine with promax, or oblique, rotation) to assure that one underlying construct is represented by each variable. The factor variable created by this process captures the common variance among conceptually similar measures while purging the index of the variance unique to each of the measures.

The index of implementation success was constructed using iterated principle factor analysis and promax rotation for the five indices used as dependent variables: legislative activities, surveillance, monitoring and evaluation, community involvement, and the ability to create a permanent place for the program within the state agency (institutionalization).

Linear regression analysis is used to assess the statistical relationship between the indicators of implementation success (dependent variables) and those factors hypothesized to influence whether injury prevention programs are effectively implemented (explanatory variables).

\section{Results}

Sixty four questionnaires were received from 68 programs representing 44 states. Sixteen states submitted two or more questionnaires from different units involved in injury prevention or control. Three questionnaires were excluded from the regression analysis because of a significant number of missing variables, leaving 61 completed surveys for regression analysis and 64 for the calculation of frequencies. Responding programs included: injury prevention or control $(n=24)$; maternal and child health $(n=12)$; health promotion/education $(n=10)$; emergency medical services $(n=8)$; epidemiology units $(n=5)$; disability prevention $(\mathrm{n}=5)$; environmental health $(n=2)$; chronic disease $(n=1)$; and health department $(n=1)$.

The following section describes state injury prevention program activities related to successful implementation, the dependent variable. Although only $20 \%$ of the programs reported that staff were permitted to contact elected officials regarding injury prevention/ control issues, $56 \%$ reported that staff were permitted to testify and advocate for injury prevention. Staff who had actually participated testified for their agencies or participated officially in advocacy activities in $64 \%$ of the responding programs.

Surveillance data were used for modifying current programs and developing new activities. by $34 \%$ and $50 \%$ of the respondents, respec tively. Allocation of resources specifically for program evaluation was reported by $53 \%$ of responding programs, with $38 \%$ having made significant changes based on results of evaluat $\frac{\bar{C}}{0}$ ing program progress.

Community involvement in program plan $\bar{\Omega}$ ning was reported by $44 \%$ of respondents with $34 \%$ involving the community in locating and acquiring resources for the program. Respondents were asked their perception of the level of success in moving toward institutionalization? Thirty six per cent felt they had made significant progress toward creating a perma nent place for injury prevention in their stateo agency.

We now present a selection of the explana= tory factors expected to influence the successe ful implementation of injury prevention programs (independent variables). The litera $=$ ture concurs with our expert panel thate characteristics of the mandates or policies are a factor that can significantly influence both thes interpretation and the implementation of the subsequent activities. The results indicate tha of the respondents who receive policy direco tives from state agency heads, $71 \%$ considered? the directives to be 'fairly' or 'moderately $\overrightarrow{\widehat{D}}$ clear. Of those that received directives from the state legislature or governor's office, $59 \%$ and $47 \%$, respectively, considered those policy directives to have fair to moderate clarity.

Programs reported that the greatest degree of administrative control was over the assign ment to specific projects and program priorities; the least degree of control was over program budget decisions and contacts with elected officials and legislators. The lack op control over budget decisions may be related to the finding that $22 \%$ of the responding programs had no full-time staff members, while almost half reported three or fewer full? time staff.

About one half of the respondents believedE. media attention significantly contributed tô their programs through increasing an aware ness of both the injury issue and the impor+v tance of prevention. Advocacy coalitions $\delta^{\omega}$ provided a moderate to high level of support to $64 \%$ of the responding programs.

The table displays the regression results. Si $\mathbb{D}^{\infty}$ dependent variables, the five indicators off implementation success and the combine $\overline{\mathrm{p}}$ index, were regressed on the same set of explanatory variables, including the combine $\vec{B}$ index of the five indicators of implementationo

Before considering each equation in turn some general observations can be made. Firsto the statistical results show that the explanatory effect of each of the variables varies for the different implementation indicators. No single variable consistently influences (in a statistical sense) implementation activities. Second, the group of explanatory variables as a whole appears to structure the success of some 
Multiple linear regression analysis of successful implementation of injury prevention programs

\begin{tabular}{|c|c|c|c|c|c|c|}
\hline \multirow[b]{2}{*}{$\begin{array}{l}\text { Independent } \\
\text { variables }\end{array}$} & \multicolumn{6}{|c|}{ Dependant variables } \\
\hline & $\begin{array}{l}\text { Legislative } \\
\text { activities }\end{array}$ & $\begin{array}{l}\text { Surveillance } \\
\text { activities }\end{array}$ & $\begin{array}{l}\text { Evaluation/ } \\
\text { monitoring }\end{array}$ & $\begin{array}{l}\text { Community } \\
\text { involvement }\end{array}$ & $\begin{array}{l}\text { Institutiona- } \\
\text { lization }\end{array}$ & $\begin{array}{l}\text { Index of imple- } \\
\text { mentation success }\end{array}$ \\
\hline Policies & 0.04 & $0.07 \dagger$ & $0.07 \dagger$ & 0.05 & 0.07 & $0.30^{\star}$ \\
\hline Administrative control & $0.18^{\star \star \star}$ & 0.01 & 0.06 & 0.07 & 0.05 & $0.36^{\star \star}$ \\
\hline Organizational capacity & 0.02 & 0.09 & $0.19^{\star \star}$ & 0.12 & $0.15^{\star}$ & $0.56^{\star \star}$ \\
\hline \multicolumn{7}{|l|}{ Ecological capacity: } \\
\hline Problem salience & -0.15 & -0.10 & 0.21 & 0.14 & $0.39^{\star}$ & 0.48 \\
\hline Constituent participation & $0.32^{\star}$ & 0.15 & $0.26^{\star}$ & $0.42^{\star \star}$ & 0.24 & $1.38^{\star \star \star}$ \\
\hline Support by elected officials & -0.11 & 0.07 & $-0.22^{\star \star}$ & -0.12 & -0.13 & $-0.51^{\star}$ \\
\hline Media attention & 0.02 & 0.06 & $0.51^{\star}$ & 0.24 & 0.19 & 1.03 \\
\hline Economy & -0.19 & -0.04 & $0.33^{\star \star}$ & -0.05 & 0.17 & 0.23 \\
\hline Constant coefficient & $4.04^{\star}$ & 1.55 & $-6.25^{\star \star \star}$ & -2.85 & 0.49 & -3.01 \\
\hline \multicolumn{7}{|l|}{ Cases $(n=61)$} \\
\hline & 0.43 & 0.29 & 0.66 & 0.42 & 0.48 & 0.69 \\
\hline Adjusted $R^{2}$ & 0.34 & 0.18 & 0.61 & 0.33 & 0.40 & 0.65 \\
\hline
\end{tabular}

Note: column entries are unstandardized regression coefficients.

Significance levels: $\dagger p<0.1,{ }^{\star} p<0.05,{ }^{\star \star} p<0.01,{ }^{\star \star \star}{ }^{*} p<0.001$.

activities while having little relationship with others. Evaluation and monitoring is most influenced by the independent variables, while surveillance activities have little or no statistical relationship with the variables.

Three variables predict legislative activities: administrative control, constituent participation, and the constant. The significance of this last variable can be interpreted to mean that where legislative contacts are already established (and the other factors are held constant at zero), success in these activities is more likely.

As noted, surveillance activities are not influenced by these independent variables, except for a weak statistical association with the attributes of policies. Evaluation and monitoring activities, on the other hand, are strongly related to organizational capacity (that is, the presence of adequate personnel), constituent participation, media attention to the issue of injury prevention, the state of the economy and the budget, and negatively related to the initial level of evaluation activities (the constant term). The support of elected officials is also a significant factor, but the direction of influence is negative. Greater attention on the part of legislators and the governor to injury programs is associated with less evaluation and monitoring effort.

Involvement of the community in the activities of injury prevention programs is not statistically related to any of the explanatory variables except constituent participation. Because these two variables measure quite similar concepts, the statistical significance of this factor is both predictable and not very meaningful. However, the institutionalization of injury prevention programs is significantly associated with the organizational capacity of the program and the extent to which the problem of injury is salient for elected officials and agency heads.

Finally, correlates of the success of implementation of injury prevention programs as a whole can be assessed. Recall that the dependent variable labeled 'implementation success' is an index constructed from all five implementation indicators and was factor analyzed to capture the underlying dimension of theoretical interest. The model that was used to guide this research performs very well. Sixty five per cent of the variance in implementation success among the 61 programs in the regression is explained by our variables, the most important of which are constituent participation, administrative control, organizational capacity, and the attributes of relevant policies. These variables are listed in descending order of importance based on the standardized coefficients.

\section{Discussion}

Whereas implementation theory is well developed, few studies have attempted to identify the relative importance of factors that lead to implementation success. This paper attempts to shed light on why certain 'critical' injury prevention program activities vary from one program to the next. It also seeks to provide practical recommendations to public health officials about how to structure organizations to implement injury prevention programs, what procedures to follow, and what resources are necessary to enhance the effectiveness of implementation efforts. To our knowledge, this is the first implementation study of a public health program.

In general, successful implementation of injury prevention programs in state agencies is related to constituent participation, administrative control, organizational capacity, and the attributes of relevant policies. Constituent participation, that is, the extent and efficacy of constituent support and advocacy, had the greatest influence on the success of program implementation. Hence, the activities of advocacy coalitions are instrumental in securing and sustaining program funding, evaluating program performance, and encouraging greater involvement of other community groups.

Another critical factor is the extent to which program managers have administrative control over resources and the setting of program priorities. The analysis indicates that where managers have administrative discretion, the programs are more likely to participate in legislative activities and demonstrate success in program implementaion. Organizational capacity, which is a function of the number of program staff and their skill levels, also is significant in predicting the level of evaluation and monitoring activities, the degree of institutionalization and implementation success. This finding is not unexpected: knowledgeable 
staff members whose time is dedicated to the program are critical for conducting the activities that our panel of experts in the field identified as necessary for injury prevention program implementation to be labeled successful. It is also not surprising that clear, easily understood policies and directives are associated with implementation success. One unexpected finding relates to the role that elected officials play in the implementation game: states where elected officials are more supportive of injury prevention efforts are likely to be less successful at implementing injury prevention programs. It should be noted, however, that injury prevention programs that are struggling may attract the attention of legislators and governors.

The results of this research are particularly important in light of the findings of a national survey of injury prevention programs in state health departments, conducted in 1988, demonstrating a high degree of variability in the development of such programs across the United States. ${ }^{10}$ The survey found that only 10 states had a separate injury prevention unit with a comprehensive program. The average number of full-time equivalent (FTE) staff devoted to injury control was 4.7 , but 22 states had one or fewer FTE working on injury prevention. Similarly, 10 states spent more than $\$ 200000$ per year on injury control, but 27 states spent $\$ 100000$ or less. It is significant to note that even the problems addressed across states varied considerably: 47 state programs related to motor vehicle occupant injury, but less than half of the states addressed the problems of burns, drowning, falls, bicycle, sport related, and other injuries. Clearly, there is room for improvement, and this study is intended to provide guidance to administrators who are seeking to expand efforts in the area of injury prevention.

Through the descriptive information provided on the written surveys and reports during telephone interviews, respondents suggested attributes and strategies they felt were key to a successfully implemented program: to encourage participation and advocacy by constituent groups, respondents reported success with establishing coalitions that linked all groups addressing injury, and developing funding opportunities for local groups to develop and implement injury prevention activities through minigrant programs for community groups.

Successful strategies for augmenting organizational capacity included pooling resources from a group of programs and agencies, utilizing insurance companies as a financial and technical resource, and subcontracting with academic institutions that offer research capabilities.

Failure to develop an infrastructure that will sustain the injury program beyond the end of grants or funding cycles places program continuation in jeopardy. Programs that must depend on internal funding will often lose their discretion over administrative control, such as program priorities and budget decisions. Respondents reported success in seeking support from private corporations and community businesses by identifying and meeting their special needs for sponsoring educational efforts and promoting community goodwill.

Attributes of relevant policies and directives play a critical part in defining the role of ap injury prevention program. Responden strongly emphasized the need to establish injury prevention as a clearly identified obje $\overrightarrow{\bar{g}_{2}}$ tive of public policy at the highest level. advisory group should be appointed by the most senior official to recommend poli related to injury prevention. Responden reported success with a strategy that organized working groups that have (1) representation from key departments and organizations and (2) leadership and members at a high admin istrative level.

To facilitate the recognition of injury as significant public health problem, respondents recommended implementing efforts specifie cally designed to educate high level people parallel agencies and the use of brief impact statements to communicate injury issues to governing officials and the community. The statement describes how a particular injury occurred and includes the "human dimensione and the actual costs of the injury.

\section{Implications for prevention}

Our findings point to specific recommend tions about the types of strategies to adopt achieve short term, targeted objectives such strengthening the program's capacity to be more effective force in the state legislature, to become more skillful at program evaluation and monitoring, or to increase the ability of the program to sustain funding after the period of initial support. Our findings also suggest th giving program administrators more discretio over key administrative decisions and mobiliz ing potential supporters among organize interests and the public could lead to increased levels of legislative activities such as providiris testimony or educating legislators on injug issues. These activities could increase the visibility of the injury problem, which, in turit should result in improved program effective ness.

If, on the other hand, improvement evaluation and monitoring capability is the goal, then program administrators must th willing to invest in hiring and training skilleg analysts. Likewise, mobilizing constituents and the media to make injury prevention more salient could also have a positive effect increasing demand for evaluation and mono itoring.

Finally, if solidifying the injury preventio program's place in the bureaucracy is the ne term goal, then making injury prevention salient issue in the eyes of government officials, and hiring and training more personnel a indicated.

The authors would like to gratefully acknowledge the support of the following: the Carnegie Corporation of New York (gran \#B5110); the NCEHIC Program Development and Implementation at the Centers for Disease Control; the Maternal and Child Health Bureau, HRSA, DHHS; and Mr Joy Nanda, data programmer/analyst. 
1 National Committee for Injury Prevention and Control. Injury prevention: meeting the challenge. (Special supple3.) New York: Oxford University Press, 1989: 1

2 Department of Health and Human Services, Public Health Service. Healthy people 2000 national health promotion and disease prevention objectives. Washington, DC: Departand disease prevention objectives. Washington, DC: Department of Health

3 Department of Health and Human Services. Press release. Washington, DC: Department of Health and Human Services, June 28, 1992.

4 Committee on Trauma Research, Commission on Life Sciences, National Research Council, and the Institute of Medicine. Injury in America-A continuing public health problem. Washington, DC: National Academy Press, 1985.

5 Rice DP, MacKenzie EJ. Cost of injury in the United States- $A$ report to Congress. San Francisco, CA: Institute for Health and Aging, University of California and Injury Prevention
Center, Johns Hopkins University, 1989: 2.

6 National Committee for Injury Prevention and Control. Injury prevention: meeting the challenge. (Special supplement to the American foumal of Preventive Medicine 5, No 3) New York: Oxford University Press, 1989: 11.

7 Gogoin ML, Bowman AO'M, Lester JP, O'Toole LJ Jr. Implementation theory and practice: toward a third generaimplementation theory and practice: toward a third generation. Glenview,

8 Mazmanian D, Sabatier $\mathrm{P}$, eds. Implementation and public policy. Glenview, II, Scott, Foresman and Company, 1983

9 Goggin ML. Policy design and the politics of implementationthe case of child health care in the American states. Knoxville: The University of Tennessee Press, 1987.

10 Harrington C, Gallagher SS, Burgess LI, Guyer B. Injury prevention programs in state health departments: a national survey. Boston, MA: Childhood Injury Prevention Center, Harvard School of Public Health, 1988.

\section{Appendix}

THE INDEX OF IMPLEMENTATION SUCCESS IS A SUMMARY MEASURE OF THE FOLLOWING ITEMS:

(1) Legislative activities

Staff are permitted to initiate contact with elected officials/legislators about injury prevention/control issues.

Staff had ever initiated contact with elected officials/legislators about injury prevention/ control issues.

Staff are permitted to be active in influence injury prevention/control legislation, that is through testifying or advocacy activities.

Staff had ever testified or participated in advocacy activities in an attempt to influence injury prevention/control legislation.

(2) Surveillance activities

Injury surveillance resulted in modification(s) of previous injury control activities.

Injury surveillance resulted in new injury control actions or activities.

There had been 'pay-offs' to the program's injury surveillance.

(3) Monitoring and evaluation

Program allocates resources specifically for evaluation of injury prevention/control activities, for example, personnel time, funding, etc.

Surveillance data/impact data are used to evaluate the programs injury prevention/control activities, that is, the results or outcomes.

Questionnaires/surveys are used to evaluate the programs injury prevention/control activities, that is, the result or outcomes.

Interviews are used to evaluate the programs injury prevention/control activities, that is, the results or outcomes.

Program conducts process evaluations to monitor the progress of the injury prevention/ control activities.

Significant changes in the activities/program had been based on the results of the monitoring (process evaluation).

(4) Community involvement

Degree of community involvement in program's injury prevention/control activities.

Community is involved in formulating ideas for the injury activities/program.

Community is involved in planning with the injury activities/program.

Community is involved in the locating/procuring resources for the injury activities/program.

Community is involved in the implementation/conduction of activities with the injury program.

Community is involved in the evaluation of the process and/or outcomes of the injury activities/program.

Community is involved in lobbying/political activities with the injury activities/program.

(5) Institutionalization - the 'permanence of the program within a larger host agency or organization'.

Activities of the program have made other state departments/agencies more aware of injury prevention/control as an important issue.

Injury prevention/control had been given a high priority in the state.

Injury prevention/control activities in the state were being effective in reducing injuries.

Program has the resources to meet the challenge of injury prevention/control in the state. 